\title{
A ARTE DE CONTAR E LER HISTÓRIAS NA EDUCAÇÃO INFANTIL
}

\author{
Denize Leite Ferreira ${ }^{1}$
}

\section{RESUMO}

O presente trabalho explora a história, a narrativa e o valioso impacto na prática para o ensino e desenvolvimento em sala de aula. Examina o a contação de histórias como processo no ensino. Discorre acerca do uso das narrativas e suas estruturas. Mostra diferentes abordagens e estratégias educativas a permitir um grande avanço no ensino-aprendizagem. Categoriza a contação de histórias como um importante mecanismo para o aprendizado, a socialização e, também, para absorção da cultura.

Palavras-Chave: Contação de Histórias. Ensino-aprendizagem. Desenvolvimento.

\begin{abstract}
This paper explores history, narrative, and the valuable impact on practice for classroom teaching and development. It examines storytelling as a process in teaching. It discusses the use of narratives and their structures. It shows different approaches and educational strategies to allow a great advance in teaching-learning. It categorizes storytelling as an important mechanism for learning, socializing and also for absorbing culture.
\end{abstract}

Keywords: Storytelling. Teaching-learning. Development.

\section{RESUMEN}

El presente trabajo explora la historia, la narrativa y el valioso impacto en la práctica para la enseñanza y el desarrollo en el aula. Examina la narración de historias como un proceso en la enseñanza. Discute el uso de las narrativas y sus estructuras. Muestra diferentes enfoques y estrategias educativas para permitir un gran avance en la enseñanza-aprendizaje. Categoriza la narración como un mecanismo importante para el aprendizaje, la socialización y también para la absorción de la cultura.

Palabras Clave: Narración de Historias. Enseñanza-aprendizaje. Desarrollo.

\footnotetext{
${ }^{1}$ Licenciada em Pedagogia e Letras, especialista em Alfabetização e Letramento. Email: denize_leite16@hotmail.com
} 


\section{INTRODUÇÃO}

Histórias vão além da arte. Alcançam patamares ainda ditos como insolúveis numa camada mais profunda e subliminar. Na maioria das vezes só nos damos conta da influência da contação de histórias depois. Estamos tão absorvidos pela narrativa/contação que não percebemos.

O fato é que histórias são usadas para educar, treinar, divertir e comunicar. Há muito escrito sobre o uso da narração de histórias na área da saúde (incluindo saúde mental) e contextos de educação em saúde, trazer mudanças positivas para os pacientes, e promover as melhores práticas para profissionais.

A contação de histórias também tem sido usado entre serviços de vendas (Cox, 2003) no mercado coorporativo, nas grandes empresas e instituições. No entanto, há menos avaliação documentada de como os impactos da narrativa na prática e no indivíduo. A evidência disponível sobre o uso de histórias em saúde, educação e mercado coorporativo aplicava-se de uma forma inconsciente. No entanto, hoje com os estudos sobre as narrativas arquétipos e estereótipos a concepção, abordagem e aplicação mudou consideravelmente.

No que diz respeito ao aprendizado, podemos afirmar que a contação de histórias é o maior veículo para se apresentar conceitos, técnicas e ideias. As estratégias educativas por esse processo permitem um grande avanço no ensino-aprendizagem. Um importante mecanismo para o aprendizado de língua estrangeira e, também, absorção da cultura.

A contação de histórias pode comunicar o físico (corpo e linguagem verbal, voz e entonação), aspectos intelectuais e emocionais de uma pessoa, o contexto de suas experiências passadas ou presentes, que permite uma compreensão mais completa do seu Eu.

Field (2012, p.123) afirma que uma boa história combina o explícito com o tácito, a informação com a emoção. Mas, diante de tudo isso, qual seria a influência das histórias na aprendizagem? O que isso resultaria? Qual seria o reflexo na formação do aluno? E o que isso causa no indivíduo?

Os objetivos do presente manuscrito é estender o conhecimento das narrativas no que diz respeito à oralidade, escrita, desenvolvimento e formação do indivíduo aos arquétipos e estereótipos presentes nas histórias, sejam elas 


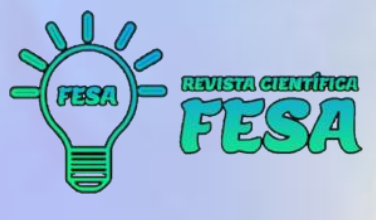

lendas, contos de fadas, histórias folclóricas, lendas urbanas. A trazer uma revisão de literatura que discorra sobre todo o processo de contação de histórias e o reflexo disso na formação da criança.

Diante da importância de consolidar e entender os conceitos e mecanismos do processo da contação de histórias definiu-se como objetivo específico: Identificar a importância das narrativas/contação de histórias na formação das crianças; Analisar a relação do processo da contação de história e o desenvolvimento da criança; e Discorrer acerca das possibilidades lúdicas e a socialização por meio das histórias.

Assim, esta pesquisa analisará a contação de histórias em diferentes vertentes, a auxiliar as organizações escolares a potencializarem as competências de seus recursos com a finalidade de unificar o conhecimento.

A globalização e as novas tecnologias levaram as escolas a sistematizarem ferramentas que até então eram usadas de forma empírica. A contação de histórias faz parte desses mecanismos e é o processo mais explorado e foi por muito tempo de forma inconsciente. As estruturas que resultam nas narrativas se tornaram ferramentas importantes na disseminação do conhecimento

Justifica-se a escolha do presente tema pela relevância do assunto e para o sucesso do ensino aprendizagem. Conscientizando-as de terem objetivos claros e definidos. A usar estruturas que, na verdade, fazem parte da realidade humana estão inseridos no inconsciente coletivo. O processo de contação de histórias traz crescimento e retorno para todos os envolvidos. Afinal, histórias encantam, resgatam e trazem modelos identidades necessárias para a vida aqui na terra.

\section{AS HISTÓRIAS E AS NARRATIVAS}

Souza (2011, p.12) afirma que sobre o objetivo das histórias, dentre as várias repostas existentes, podemos destacar o resgate cultural na tradição de contar histórias tanto para crianças quanto para adultos. Elas são registros vivos de nossa sociedade e carregam importantes informações de nossos ancestrais quer seja por mitos ou fatos.

Cunha (2003, p.56) afirma que as histórias promovem uma independência no pensar e no desenvolvimento do saber. Elas vão de encontro com a postura 


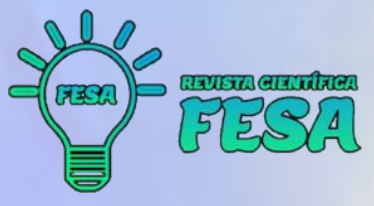

autoritária que adultos adotam perante a criança, oferecendo-Ihe aquilo que acham ser o melhor para ela, sem buscar observá-la e apreender suas necessidades, seja pela conversa sincera ou pelas suas manifestações concretas: gestos, atitude de recepção ou não, expressão corporal diante de uma história que está sendo contada.

É preciso lembrar que a criança é um ser ativo, que não digere informações apenas, elas as transformam e recriam em função de suas necessidades e experiências. A criança é totalmente capaz de manifestar, de acordo com a idade e suas capacidades aquilo que the agrada ou não. Quanto às cantigas de roda, que eram cantadas para ninar os bebês, ou para brincar na rua, na escola, nos encontros com os amigos e parentes, parecem ter perdido espaço para outras atividades. (CUNHA,2003, p.112).

Costa (2007, p.105) afirma que as histórias trazem autonomia pois carregam uma informação que muitas vezes passou de geração por geração. Esse ponto de equilíbrio sobre a realidade e a fantasia é desenvolvido pelo aluno no momento em que entra em contato coma narrativa.

[...] as coisas antigas, aparentemente há muito esquecidas, são preservadas dentro de nós, elas continuam a agir dentro de nós frequentemente sem que as percebamos - e de repente vêm a superfície e começam emergir [...]. Em diferentes períodos, dependendo da situação social e das necessidades das classes em ascensão ou em declínio, diversas coisas que permaneciam latentes ou eram dadas como perdidas são trazidas à tona. (COSTA, 2007, p.35).

Desde que os seres humanos se sentaram ao redor do fogo em cavernas, eles contaram histórias para ajudá-los a lidar com a vida e a luta pela sobrevivência (MCKEE; FRYER, 2002, p. 98). Histórias nos dão uma visão mais profunda da experiência vivida passado, presente e imaginado futuro (MCADAMS, 2007, p.23). Pode-se argumentar que a arte de contar e ouvir histórias está no coração e traduz um significado existencial para o ser humano. Revela como os seres humanos articulam suas experiências de mundo e como fazer sentido disso.

História é a narração dos fatos notáveis ocorridos na vida dos povos, em particular, e da humanidade, em geral. Um conjunto de conhecimentos, adquiridos através da tradição e/ou mediante documentos, acerca da evolução do passado da humanidade. Ciência e método que permitem adquiri-los e transmiti-los. Narração de acontecimentos, ações, fatos ou particularidades relativas a um determinado assunto. 
[...]. Estória é: narrativa de ficção; exposição romanceada de fatos puramente imaginários (distinta da história, que se baseia em documentos ou testemunhos); conto, novela, fábula: estórias de quadrinhos./ Ant. História. (FERREIRA, p. 454, 2008).

Figura 1. Cena do filme A Guerra do Fogo

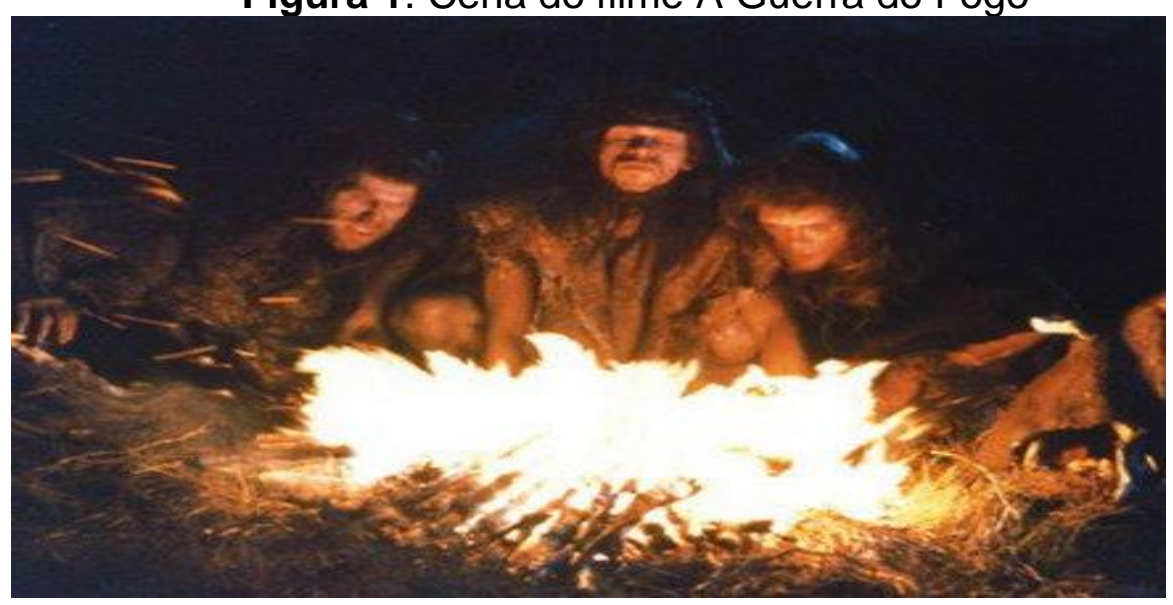

Fonte: Revista Set.

Esta revisão explora a história e a narrativa e o valioso impacto na prática que e pode gerar mudanças positivas e significativas para a humanidade. Examina como contação de histórias tem sido usada em todos os serviços sociais até o momento, considera seu valor e destaca algumas considerações para quem cria e usa histórias. Provas de estudo de caso são fornecidas para mostrar benefícios da narrativa na prática.

Uma história é um acontecimento real ou imaginado de eventos que descrevem a experiência humana. Os termos "História" e "Narrativa" são frequentemente usados de forma intercambiável. Contudo, algumas pesquisas destacam que a história é a informal forma de contar a experiência vivida, enquanto a narrativa é uma interpretação estruturada da história, que inclui adições e omissões. (Hardy, 2011, p.143).

Nas palavras de Vogler (2007, p.203) "Storytelling é a contação individual de um evento para criar uma imagem memorável na mente do ouvinte". Estudos de Mckee (2002, p.62) e Vogler (2007, p.99) já ofereciam um comparativo de definições, essencialmente baseadas em palavras e ações sendo usadas para descrever uma sequência de eventos e evocar a imaginação do ouvinte.

Enquanto contar histórias envolve muitas vezes pessoas e situações sem o uso de impressão ou tecnologia, vídeo e áudio modernos, atualmente tornouse mais fácil utilizar esse processo graças a tecnologia. A tecnologia fornecer 
oportunidades para as pessoas criarem e divulgarem histórias muito mais amplamente e informalmente.

Souza (2011, p.105) afirma que as histórias podem ser orais, escritas, visuais ou digital vários formatos e em vozes diferentes. A narração está sujeita à maneira como pessoa usa oral (incluindo linguagem corporal se visual) e linguagem escrita ou imagens. Diante da importância de consolidar ideias e, principalmente, estabelecer um contato com o conhecimento as diretrizes educacionais do mundo moderno recorreram à contação de histórias e no conjunto de arquétipos e estereótipos com base em estruturas estereotipadas para ir além do "novo", das "regras". A contribuição do processo de contação de histórias pedagogicamente falando transita por entre todas as disciplinas e tipologias de ensino.

\section{A CONTAÇÃO DE HISTÓRIAS EM SALA}

O uso de narrativa na sala de aula cria um bom ambiente de aprendizagem e fornece contribuição significativa e compreensível. Por meio das histórias, o dispositivo de aquisição de idioma é ativado e é fácil para as crianças induzirem a linguagem elementos dos dados fornecidos pelas histórias (KRASHEN, 1981, p.13).

Contar histórias tem valores pedagógicos especiais para a sala de aula de língua estrangeira.

As histórias são eficazes como ferramentas educacionais porque são crível, memorável e divertido. A credibilidade decorre do fato de que as histórias lidam com a experiência humana que tendemos a perceber como uma fonte autêntica e credível de conhecimento. Histórias tornam a informação mais memorável porque eles nos envolvem em ações dos personagens. Ao fazê-lo, histórias convidam a criação de significado ativo. (ROSSITER, p.88, 2002).

Para Abramovich (1989, p.22), são inúmeros os benefícios da contação de histórias e da literatura. Alunos de idiomas podem se beneficiar da narrativa porque as histórias os ajudam a desenvolver a habilidade para entender a linguagem falada e se envolver em habilidades de pensamento. Em conexão com isso, Castro (2002, p. 52) relata um estudo realizado na Colômbia e enfatiza que: 
Ouvir histórias desenvolve a escuta e a concentração das crianças habilidades e sua capacidade de receber e entender informação expressa em palavras. Além disso, com as histórias crianças desenvolver estratégias de aprendizagem, tais como ouvindo o significado geral, prevendo, adivinhando significado e hipótese. (CASTRO, 2002, p. 52)

Figura 2. Storytelling

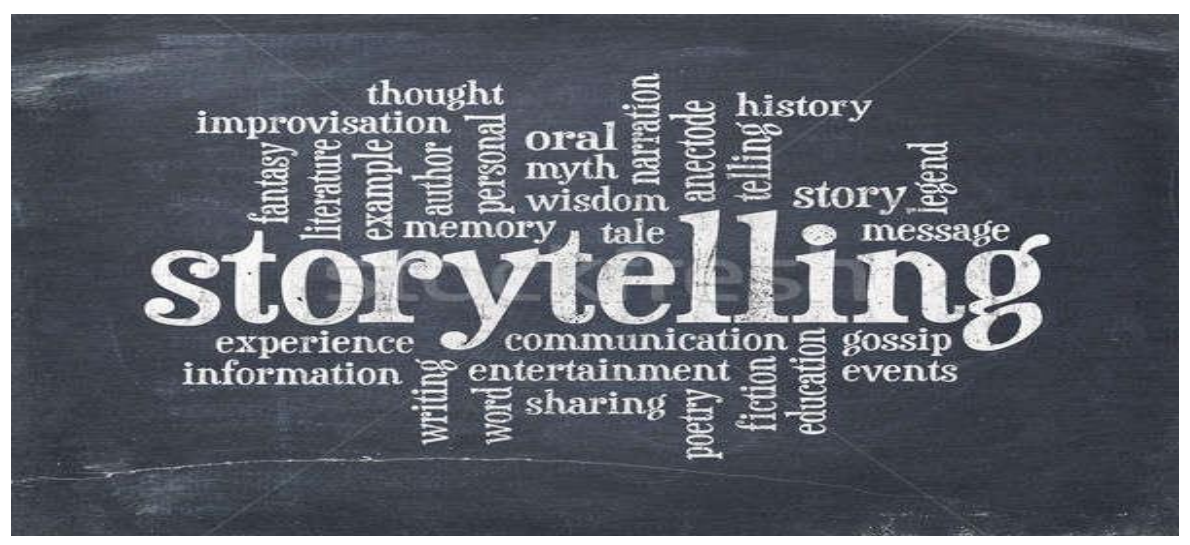

Fonte: Storytellers contend.

Por meio das histórias, os aprendizes tornam-se conscientes de valores culturais diferentes dos deles, aguçar sua memória e desenvolver a capacidade de prever e inferir.

\section{A CONTAÇÃO DE HISTÓRIASE A LÍNGUA ESTRANGEIRA}

Abramovich (1989, p.32) ressalta que a Contação de histórias e a literatura fornecem para os alunos a oportunidade de falar uma língua estrangeira de forma criativa, integrar informações e conhecimentos que aprendem de outras fontes a tornarem-se mais confiante na capacidade de se expressar espontaneamente.

Segundo Curtain \& Dahlberg (2004, p.96), narrativa pode fornecer experiência com o modo interpretativo para crianças, mesmo em muito cedo fases de aquisição da linguagem, quando as histórias atender aos seguintes critérios: a história é altamente previsível ou familiar para as crianças de sua cultura nativa, com uma grande proporção de vocabulário previamente aprendido. Nos estágios iniciais, é especialmente útil escolher histórias que incluam vocabulário representando a casa e a escola ambientes das crianças.

\section{CONMRGÂNAASTEÓRICASDOMNDOCONIEMPORÂNEO}




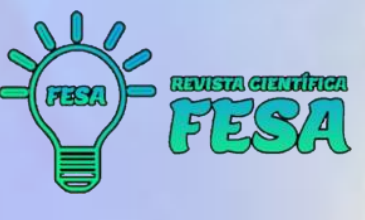

Souza (2011, p.103) afirma que a história é repetitiva, fazendo uso de fórmulas e padrões que ocorrem regularmente e previsivelmente. Nas melhores histórias escolhidas, esses elementos repetidos fornecer linguagem que as crianças podem usar mais tarde para seu próprio propósito expressivo.

Cameron (2001, p.170) define este padrão repetitivo em uma história como paralelismo. "O padrão de previsibilidade + surpresa, ou repetição + mudança é frequentemente refletida em padrões de repetição da linguagem.

Para Cunha (2003, p.33), este padrão repetido, ou paralelismo, cria um caminho para a história para o ouvinte ativo, bem como fornecer um suporte natural para a aprendizagem de línguas." histórias são memoráveis, como a linguagem é repetida, e isso incentiva os alunos a participar.

Esta reciclagem de padrões incita os alunos a prever o que vem a seguir na história e, ao mesmo tempo, exercita sua imaginação. Além do que, além do mais, Lipton (1998, p.223) ecoa a ideia de participação por parte dos alunos, dizendo que a história ideal "deveria ter um refrão curto que é repetido periodicamente ao longo da história, de modo que depois de um tempo as crianças naturalmente gritam e repita o refrão sem ser perguntado".

Quando as histórias atendem a esses critérios, é muito mais fácil para os alunos para tornar o significado claro não só porque as histórias são relacionadas ao seu real ambiente de vida, mas também porque o uso de pantomima e linguagem corporal fazem a história mais compreensível para os alunos. Por outro lado, as histórias contêm padrões que ajudam os alunos para se familiarizar com e internalizar uma nova linguagem.

\section{LEITURA DE HISTÓRIAS}

Ler histórias em voz alta permite que as crianças façam conexões entre a linguagem oral e a impressão que representam essa linguagem oral. Enquanto lê em voz alta, o professor deve apontar para a palavra ou linha para enfatizar essas conexões. O propósito de ler histórias é dar aos alunos a linguagem oral entrada e uma ponte para a alfabetização na nova língua.

Para ler histórias nos primeiros estágios da linguagem, o professor deve primeiro fazer muitas pré-leituras trabalho que prepara o aluno para poder. Este trabalho de pré-leitura é focado na construção de vocabulário 
através de diferentes tipos de atividades, como jogos, quebra-cabeças, correspondência atividades, músicas e outros tipos de atividades que ajudam os alunos para se familiarizarem com a nova língua.

Depois de ler a história em voz alta, o aluno pode ser envolvido numa variedade de tarefas de pós-leitura e atividades de linguagem que podem tornar a história mais compreensível e movê-los de forma receptiva às habilidades (ouvir e ler) para habilidades produtivas (falando e escrevendo). Sobre a importância de um grande livro, com ritmo impactante e histórias envolventes, Curtain \& Dahlberg (2004, p.254) falam a respeito:

\begin{abstract}
Um grande livro é uma peça ampliada de comerciais ou feitos por estudantes literatura, destinada a recriar a intimidade e os bons sentimentos de sessões one-on-one de "leitura em voz alta" com uma turma inteira. Então eles são grandes o suficiente para que toda a turma possa ver e compartilhar experiência. A maioria dos grandes livros tem uma história previsível com ritmo forte, rima, padrões repetidos, sequência lógica e ilustrações de apoio. (CURTAIN; DAHLBERG, 2004, p.254)
\end{abstract}

Souza (2011, p.107) discorre acerca da importância da oralidade no processo de ensino aprendizagem e destaca o papel da contação de histórias. Neste sentido, uma ferramenta importante é a leitura de histórias em voz alta é o uso de grandes livros. Ao ler em voz alta, grandes livros tocam papel importante, pois podem ser uma boa fonte para professor e alunos fazerem conexões entre as imagens e o texto escrito. As fotos nos grandes livros ajudam muito as crianças porque eles podem associar fotos e palavras e chegar a uma melhor compreensão da história.

Segundo Costa(2007, p.188) grandes narrativas projetam imagens, uma história é memorável se relacionada a uma sequência de fotos. Grandes livros se tornam uma ferramenta muito envolvente para lendo em voz alta; eles são feitos de ótimas ilustrações que ajudam os alunos a entender a história como bem como fazer previsões. Eles incluem textos curtos com padrões repetidos que permitem aos estudantes interiorizar o novo vocabulário e estruturas em uma maneira agradável e inconsciente. 
Figura 3. Leitura de histórias em voz alta e o uso de grandes livros

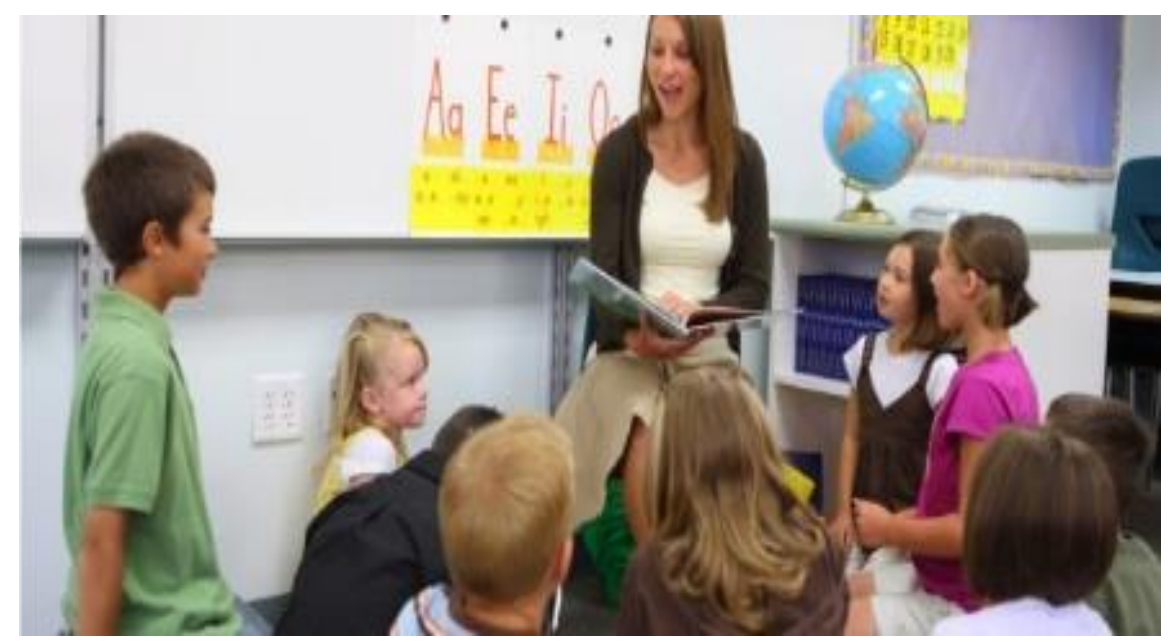

Fonte: Giracirandinhas.

As crianças gostam de ouvir histórias repetidas várias vezes; esta repetição permite-lhes adquirir certos itens de linguagem e reforçar outros inconscientemente. Usando histórias permite aos professores introduzir novos vocabulário expondo as crianças à linguagem em diferentes contextos, enriquecendo assim o seu pensamento habilidades e introduzindo-os para as habilidades produtivas.

Além disso, como observado por Ellis \& Brewster (2002, p.232), muitas histórias têm repetição natural do vocabulário chave e estruturas que ajudam as crianças a lembrar detalhes e aprenda a antecipar o que está prestes a acontecer a seguir na história.

Histórias repetitivas são particularmente fáceis para crianças para memorizar. Repetição ajuda as crianças aprenda os padrões e a estrutura de uma história e, eventualmente, reconhecimento de palavras. Repetição faz livros previsíveis e ajuda a desenvolver o vocabulário e sequenciamento.

Ferreira (2008, p.96) discute questões acerca de estruturas de melhor assimilação para os alunos e como isso acontece. Padrões repetitivos podem ser esquema para a compreensão dos alunos e por serem capazes de prever a ação na trama e no fim, a leitura flui de forma lúdica e sistemática. Frases e eventos recorrentes podem ajudar na sua compreensão e memória. Além disso, a repetição apresentava no texto é uma ótima maneira para as crianças melhorarem suas habilidades de leitura. Também Ihes dá uma base forte para desenvolver a confiança para passar para mais textos interessantes e 
complexos.

\section{APRENDIZADO: AS CRIANÇAS E AS HISTÓRIAS}

O que ajuda as crianças a aprender de uma maneira divertida e significativa são histórias criadas de acordo com as suas realidades. A análise de necessidades e interesses é muito importante porque conhece as preferências dos alunos e interesses ajudando a implementar uma abordagem pedagógica proposta que as crianças encontrem significativa e interesse.

Aprender é algo interessante e agradável. Os professores devem levar em conta seus gostos e interesses. É uma forma de conectar ao novo aprendizado com suas vidas. A criança terá uma melhor compreensão das histórias e permitiu-Ihes ter sucesso ao ler porque fizeram conexões com suas experiências anteriores com o texto.

Segundo Curtain \& Dahlberg (2004, p. 143) ressaltam que a "experiências de leitura significativa tanto em primeira como salas de aula de segunda língua são dependentes da compreensão da linguagem oral dos alunos e também no conhecimento prévio existente dos alunos e sua experiência. À medida que os alunos desenvolvem sua escuta/compreensão, eles começam a fazer conexões entre a linguagem oral e a impressão que representa esta linguagem oral.

Figura 4. Storytelling em sala de aula

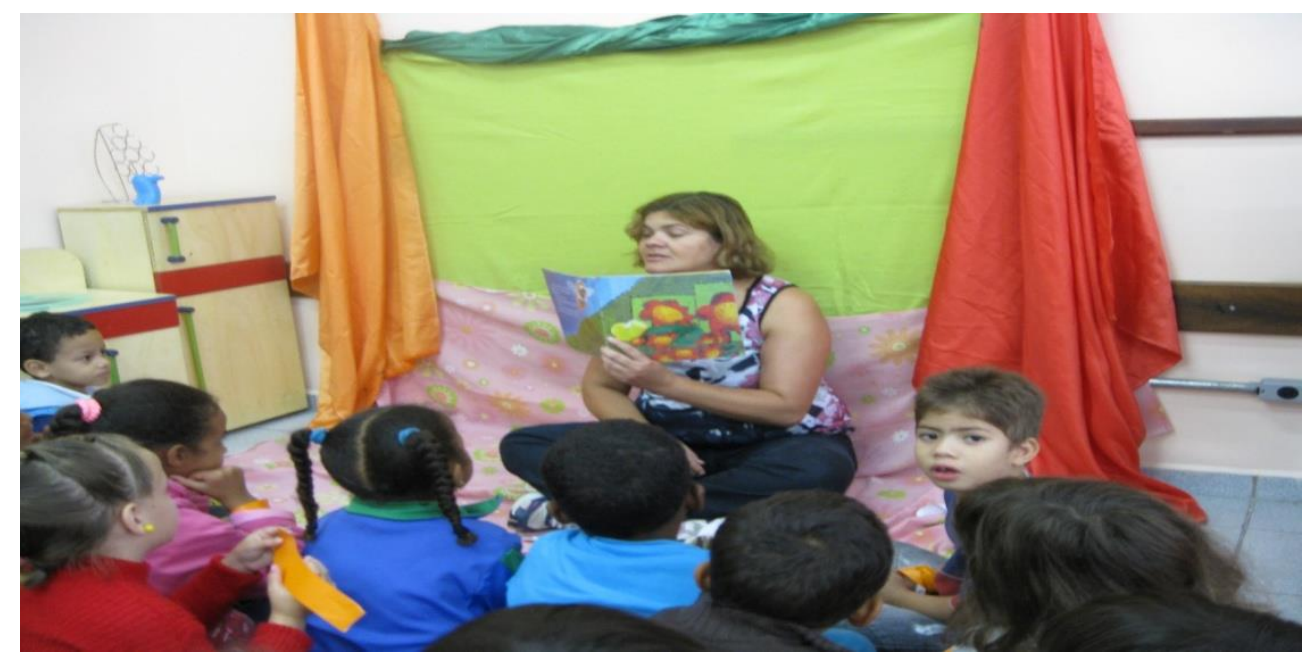

Fonte: Gira cirandinha. 
Para ajudar os alunos a ter uma melhor compreensão de um texto de leitura, é muito útil prepará-los ativando seus conhecimentos, não só na língua-alvo, mas também em sua primeira língua.

A Compreensão de leitura depende muito das experiências e informações anteriores já armazenadas na memória dos alunos. Por outro lado, deve haver trabalho intensivo por meio de diferentes tipos de atividades orais antes de ler para garantir compreensão e compreensão dos alunos sobre o que eles vão ler. Uma vez que os alunos estejam familiarizados com a nova língua através de atividades orais, eles estão prontos para enfrentar o texto escrito.

\section{POR QUE COMPRAMOS/CONSUMIMOS TANTAS HISTÓRIAS?}

A resposta mais rápida seria: diversão, distração, entretenimento. Mas, afinal, o que é entretenimento?

Ser entretido é emergir na cerimônia da história para um fim intelectual e emocionalmente satisfatório. Nosso apetite por narrativas (filmes, séries, livros, HQs, games, músicas) é um reflexo da necessidade profunda do ser humano em compreender os padrões do viver, não meramente como um exercício intelectual, mas como uma experiência pessoal e emocional.

\section{QUAL A IMPORTÂNCIA DA HISTÓRIA PARA AS NOSSAS VIDAS?}

A vida não nos informa como ser vivida. Precisamos de modelos. Os contadores de história oferecem insights sobre as formas e trazem em suas narrativas esses padrões.

A história não é uma fuga da realidade, mas um veículo que nos carrega em nossa busca por ela.

Quando a história está em sua mente, você percebe sua relevância para com aquilo que esteja acontecendo em sua vida. Isso dá perspectiva ao que Ihe está acontecendo. Com a perda disso, perdemos efetivamente algo, porque não possuímos nada semelhante para pôr no lugar. (CAMPBELL, p. 65, 1988). 


\section{ABORDAGENS EM SALA DE AULA}

Ferreira (2008) afirma que ao contar essas histórias em sala de aula, a professora pode se caracterizar igual aos personagens. E, em outros momentos, pode usar um jaleco "MÁGICO" específico de contação de histórias. Dessa forma se pretende enfatizar o respeito, valorização e inclusão de raça, de valores e incentivar à leitura de forma lúdica e prazerosa. Os personagens serão Dona Baratinha, Menina Bonita do Laço de Fita.

Cada história traz uma mensagem em sua concepção estereotipada. Veremos abaixo a representação de umas delas:

\section{PINÓQUIO}

A história do boneco de madeira Pinóquio é uma história sobre inclusão. São inúmeras as referências acerca do processo inclusivo. Há um forte apelo a boa conduta e bons comportamentos boas companhias. E uma análise sobre a mentira e suas consequências.

Figura 5. Pinóquio

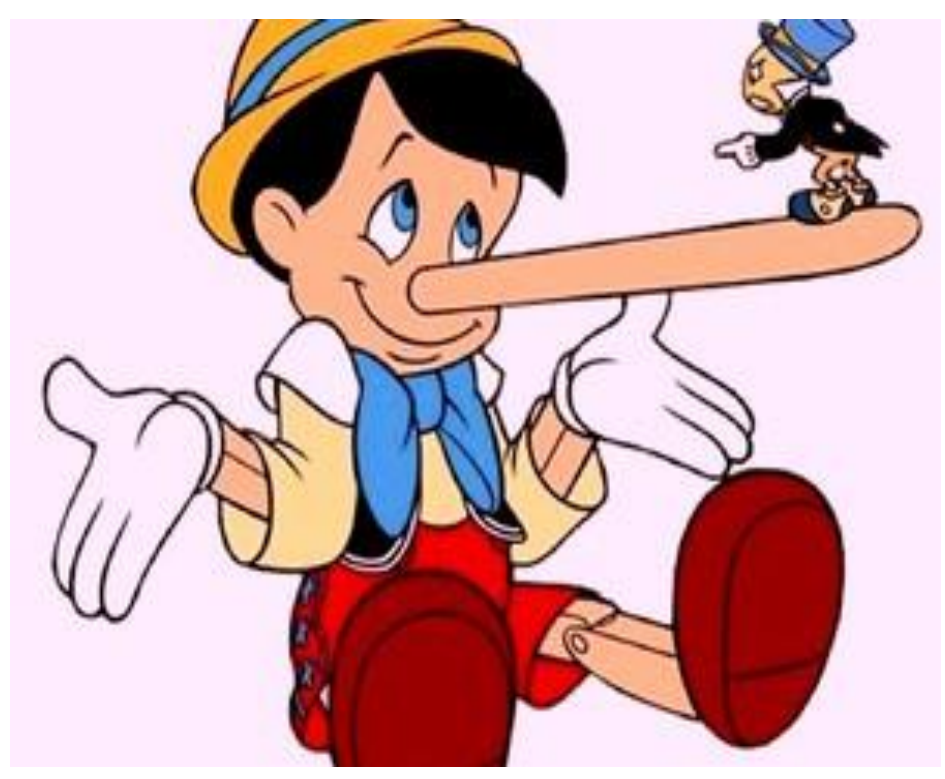

Fonte: G1 - Globo.com.

\section{CONERGÊNAASTEÉRICASDOMNDOCONIEMPORÂNEO}




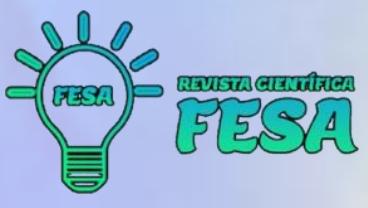

Conta a história de um garoto que tinha um defeito, era um boneco de madeira. Era diferente e isso fazia dele um garoto solitário. Sonhava em se tornar um menino de verdade. No entanto, quando se torna um garoto de verdade faz coisas ilícitas que o levam a ruína. Moral da história: O que importa não é o que você tem, mas sim quem você é. A beleza, a igualdade está dentro de cada um.

A bela narrativa de Pinóquio segue os doze passos da Jornada do Herói e traz as concepções do declínio moral de um personagem que via apenas o mundo exterior. É uma forte reflexão sobre as diferenças. Há o momento de retirada do herói um dos doze passos da jornada do Herói, um momento para reflexão. Aqui, este momento acontece no ventre de um peixe.

Figura 6. Ventre do peixe

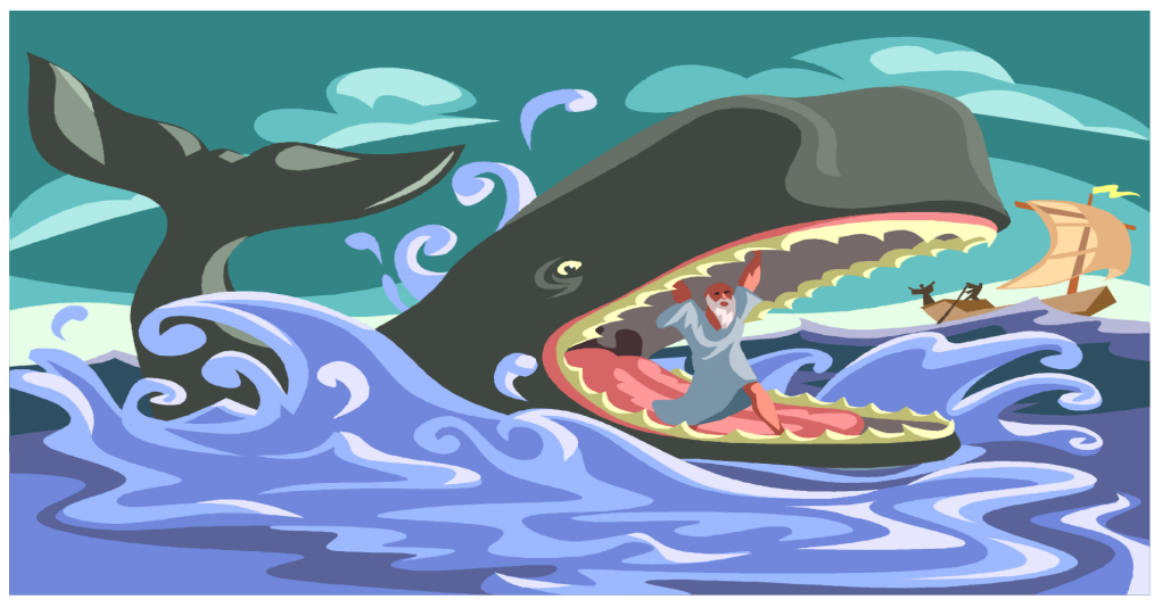

Fonte: http://www.marcelodalla.com.

O ventre da baleia é uma importante passagem. Requer reflexão aprofundada. E é importante fazer uma comparação acerca dessa estrutura estereotipada. Seu significado é crucial para a formação das crianças. A simbologia às vezes é representada pelo deserto, monte ou buraco/gruta.

\section{MARIA BONITA DO LAÇO DE FITA}

A história leva a reflexão de algumas questões e dessa forma as crianças podem pensar e verbalizar suas opiniões. Após a troca de opiniões, informações, deve-se retornar a contação do trecho da história. "O coelho

\section{CONERGÉNAASTEÓRCASDOMNDOCONIEMPORÂNEO}


achava a menina a pessoa mais linda que ele já tinha visto toda a vida! $\mathrm{E}$ pensava: Ah, quando eu casar quero ter uma filhinha pretinha e linda que nem ela!". As crianças serão questionadas: O que é ser bonito? Como uma pessoa deve ser para ser bonita?

Figura 7. Maria Bonita e o coelho

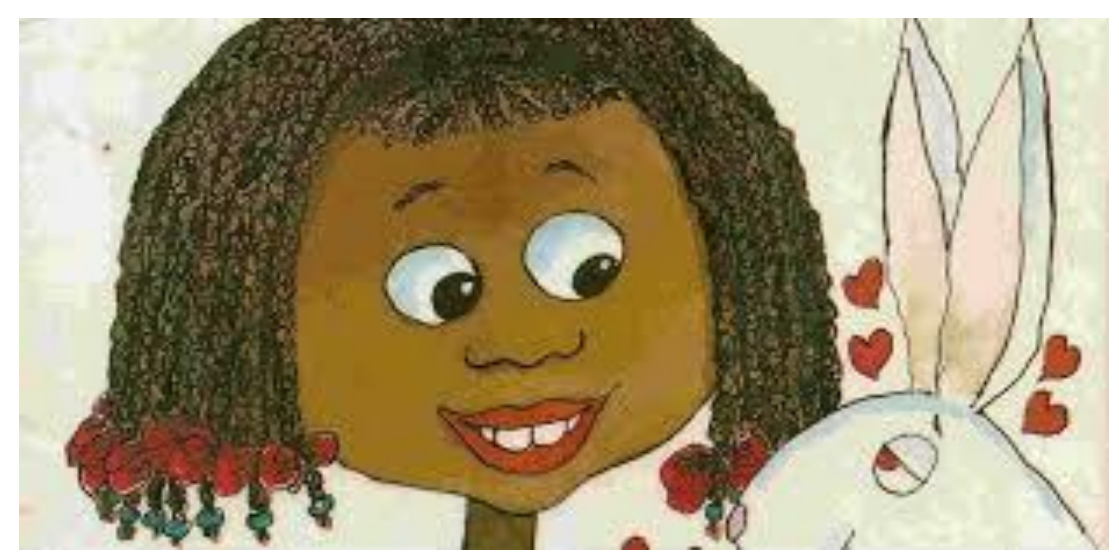

Fonte: Contação de histórias Sesc.

Durante o bate-papo, deve-se enfatizar a importância das diferenças. O ser humano como ser único. Apresentar a importância de sermos diferentes enfatizando a seguinte questão: Já pensaram se todos nós fôssemos iguais?

\section{DONA BARATINHA}

Dona Baratinha é um clássico da contação de história infantil e tende a fazer as crianças trabalharem de forma lúdica a cada frase da história. A narrativa empolga, diverte e proporciona momentos importantes quando 0 assunto é trabalho em equipe. 
Figura 8. Dona Baratinha

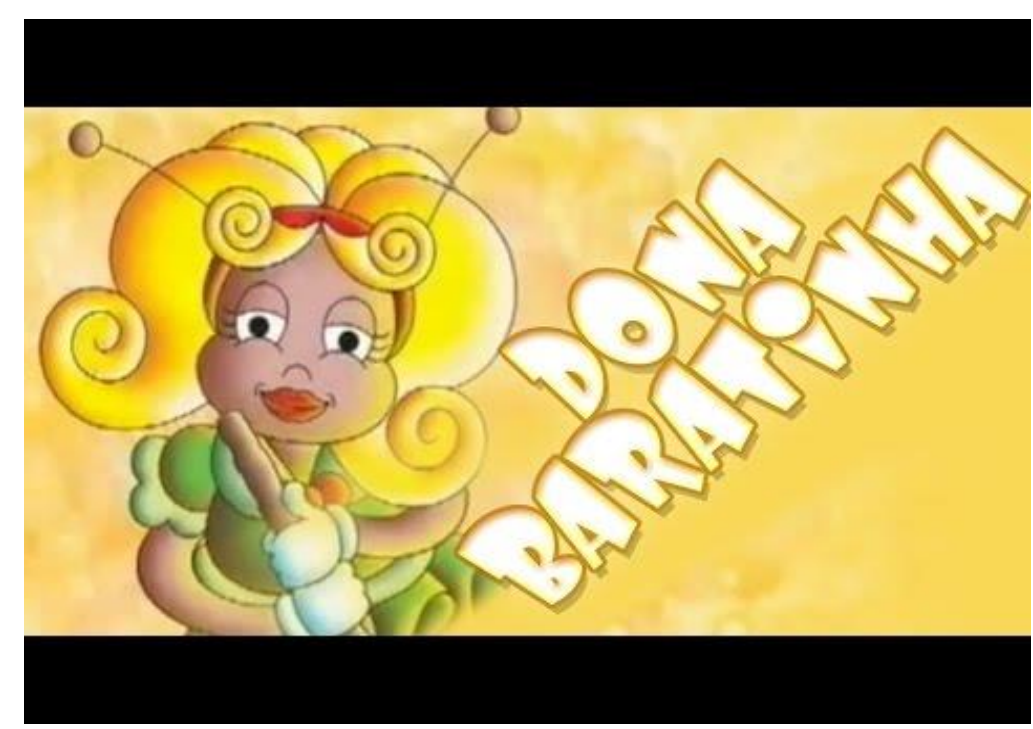

Fonte: youtube.

Dona Baratinha encanta a todos e leva os alunos a se envolverem cada vez mais com a história.

A história, assim como todas as outras, melhora o nível de alfabetização; possibilita emoções; desenvolver a oralidade; Estimula a imaginação e fantasia, desenvolve o gosto pela leitura. Dona Baratinha leva os alunos a trabalharem em equipe confeccionando presentes para o casamento e isso pode ser feito com materiais recicláveis.

Fazer a lista de convidados. Proporciona práticas de dança e movimentos, além de levar os alunos a Interpretar os personagens.

\section{PLANO DE ENSINO}

Ao que Ferreira (2008) propõe como ideia de plano de aula a ser trabaIhado. As aulas terão uma hora de duração e serão divididas em três etapas: A história contada e encenação; A reflexão da história (mensagem); e Interação/participação dos alunos. Tais etapas buscam conduzir o aluno ao desenvolvimento do senso crítico, tornando-o um leitor e produtor eficaz de histórias; utilizar, adequadamente, e reconhecer a Língua Portuguesa e os diferentes níveis de linguagem; e interagir na escrita e na fala. 
De modo mais específico, busca-se analisar e discutir os mais variados temas; compreender as mensagens das histórias; desenvolver a habilidade de comunicação em público; e produzir histórias, narrativas.

Partindo do princípio de que toda e qualquer produção literária é um fenômeno artístico vivo e dinâmico, o trabalho apresentará os conteúdos essenciais para a contação de histórias e leitura, tais como, a concepção da construção de narrativas sobre o ponto de vista de estruturas arquetípicas e estereotipadas de Joseph Campbell o Monomito. A abordagem de design textual, estruturas e substâncias, de Robert Mckee construção de cenas, trama e empatia.

Outro ponto seria a estrutura mítica de Christopher Vogler com o potencial das narrativas arquetípicas e estereotipadas nas esferas coorporativas e no mundo do marketing desvendado por Mark e Pearson. Por fim, as metodologias utilizadas estarão voltadas para a formação de uma criança autônoma, capaz de interagir com a realidade que se apresenta.

Ferreira (2008) afirma que devem ser estabelecidas relações entre a história da literatura e a cultura. $O$ aluno, assim, desenvolverá habilidades específicas além de ampliar seu repertório cultural.

As estratégias práticas compreendem na "recontação" da história pelos alunos. Cada um analisará e contará a sua versão da mesma história.

\section{CONSIDERAÇÕES FINAIS}

Os professores devem selecionar a metodologia apropriada e didática, a fim de tornar a aprendizagem interessante e significativo para as crianças.

O uso de histórias e a metodologia lúdica tornou o processo de aprendizagem de línguas significativo e divertido para as crianças.

Histórias são ferramentas para se utilizar na aprendizagem de língua estrangeira. Elas desenvolvem nas crianças a capacidade de absorver a linguagem quando as atividades são familiares e agradáveis. Assim, ensinando língua estrangeira por meio de histórias se cria um ambiente de aprendizagem que é ao mesmo tempo familiar e divertido.

Finalmente, deve-se enfatizar que a pesquisa é uma maneira eficaz para os professores melhorarem práticas pedagógicas. Por meio dela, professores, estudantes podem refletir sobre a prática, ajudando a melhorar o processo de 
ensino e encontrar melhores estratégias para ajudar os alunos a se tornarem bem-sucedidos no processo de ensino-aprendizagem.

\section{REFERÊNCIAS BIBLIOGRÁFICAS}

ABRAMOVICH, F Literatura Infantil gostosuras e bobices. Editora Scipione, 1989.

CAMERON, L. Teaching languages to young learners. Cambridge: Cambridge University Press. 2001.

CAMPBELL, J. O Herói de Mil Faces, Ediouro, Edição 2. 1988.

COSTA, P.L.; VALDEZ, D. Ouvir e viver história na Educação Infantil: um direito da criança. São Paulo: Alínea. 2007.

BORDEN, W. 'Narrative perspectives in psychosocial intervention following adverse life events', Social Work,37(2), pp. 135-4, 1992.

BORDEN, W. 'Narrative perspectives in psychosocial intervention following adverse life events', Social Work,37(2), pp. 135-4, 1992.

CUNHA, M.A.A. Literatura infantil: teoria e prática. São Paulo: Ática, 2003.

CURTAIN, H.; Dahlberg, C. A. Languages and children: Making the match. Boston: Pearson Education. 2004.

ELLIS, G.; BREWSTER, J. Tell it again: The new storytelling handbook for primary teachers. United Kingdom: Pearson Education. 2002.

FERREIRA, A. Contar histórias com arte e ensinar brincando: para educação infantil e séries iniciais do ensino fundamental. Rio de Janeiro, Wak, 2 ed. 2008.

FIELD.S. Screenwriter season: about stories. Peguin, 5 ed. 2012.

HARDY, P. An investigation into the application of the Patient Voices digital stories in healthcare education: quality of learning, policy impact and practicebased value. Belfast: University of UlsteR. 2007.

KRASHEN, S. D. Second language acquisition and second language learning. Oxford: Pergamon Press. 1981.

KRASHEN, S. D., \& Terrell, T. The natural approach: Language acquisition in the classroom. Hayward, CA: Alemany Press. 1983.

LIPTON, G. Practical handbook to elementary foreign language programs. Lincolnwood, IL: National textbook. 1998. 
MACHADO, R. A. Fundamentos teóricos-poéticos da arte de contar histórias. São Paulo: DCL. 2004.

MARK, M; PEARSON, C.S; O Herói e o Fora-da-lei. Cultrix; Edição: 2ª 2003.

MCKEE, R.; FRYER, B. Storytelling that moves people. Harvard Business. 2003.

MCLEAN K.C. Selves creating stories creating selves: a process model of self development, Altl, Click.2007.

NUNAN, D. Second language teacher education. Cambridge: CUPress. 1990.

OWOCKI, G. Comprehension "Strategic Instruction for K-3 students. Portsmouth, NH: Heinemann Educational Books. 2003.

ROSSITER, M. Narrative and stories in adult teaching and learning. (Report No. EDO-CE-02241). Washington, DC: Education Resources Information Center. 2002.

SOUZA, L.O. A contação de histórias como estratégia pedagógica na educação infantil e ensino fundamental. Revista Educere, v.6, n.12.

VOGLER, C. A jornada do escritor. Aleph. 2007. 